\title{
PERAN GURU PPKN DAN ORANG TUA DALAM PENDIDIKAN MORAL BAGI GENERASI MUDA
}

\author{
Yoga Ardian Feriandi ${ }^{1}$, Galih Puji Mulyoto ${ }^{2}$ \\ UNIPMA ${ }^{1}$, STKIP PGRI Ngawi \\ yogaardianferiandi@unipma.ac.id,newiota@gmail.com
}

\begin{abstract}
Abstrak
Moral menjadi sesuatu yang dipersalahkan atas berbagai macam keburukan yang terjadi, untuk itu orang tua dan guru patut memperhatikan moralitas genrasi muda dengan seksama. Karena generasi muda merupakan tulang pungung jalanya kehidupan berbangsa dan bernegara kelak di masa depan. Untuk itu pada artikel ini akan mengulas mengenai bagaimana peran orang tua dan guru dalam mendidik moralitas bagi generasi muda. Dari hasil pemmbahasan dapat disimpulkan bahwa Dari peran yang dapat dilakukan guru guna mendidik moral generasi muda seperti memotivasi, mengarahkan, menjadi inisiator, menjadi informator, menjadi evaluator, serta menjadi fasilitator yang baik bagi siswa maka tindakan moral siswa juga akan semakin baik. Selain itu diperlukan juga peran oang tua untuk dapat mengasuh anaknya dengan pola asuhan yang tepat yakni otokraitf.
\end{abstract}

Kata kunci: Peran Guru, Peran Orang Tua, Pendidikan Moral

\section{PENDAHULUAN}

Berbagai permasalahan yang ada di masayarakat dewasa ini agaknya selalu dihubung-hubungkan dengan moral. Sebagai contoh Kabupaten Ngawi, terdapat siswa yang melakukan tindakan asusila bersama pacarnya di salah satu SMP di Ngawi (Jawa Pos. 21 Februari 2007, p. 27). Contoh lain yakni pada tanggal 24 April 2014 lalu terdapat pelajar SMP yang digrebek warga saat melakukan tindakan asusila di rumahnya. Selain itu, terdapat pula kenakalan remaja di Kabupaten Ngawi yang melakukan tindakan pencurian kendaraan motor (Sinar Ngawi. 24 April 2014, p. 1) hingga kasus korupsi yang marak kita lihat beritanya di media cetak maupun online, semua perilaku buruk dianggap terjadi karena rendahnya moralitas.

Banyak faktor yang menyebabkan menurunya moralitas seseorang misalnya disebabkan oleh tayangan televisi, dari kajian yang dilakukan oleh Santrock (2010: 269) dapat diketahui bahwa kekerasan yang dilihat di televisi dapat mempengaruhi penalaran moral mereka pada tindakan yang agresif. Maksudnya adalah ketika anak-anak melihat acara TV yang berbau kekerasan mereka akan memiliki anggapan bahwa melalukan kekerasan dapat dibenarkan. Selain televisi internet juga memberikan sumbangsih terhadap menurunya moralitias genarasi muda, dengan menggunakan internet generasi muda dapat melihat nilai-nilai yang berkembang di luar secara mudah untuk kemudian mereka adopsi pada kehidupan bermasyarakat. Tidak jadi masalah jika nilai-nilai yang mereka adobsi tidak bertentangan dengan nilai yang ada di masyarakat, sayangya justru nilai-nilai yang negatif yang banyak di adobsi generasi muda kita saat ini. Misalnya Minum-minuman keras, seks bebas, penalahgunaan obat-obatan terlarang, dll.

Meskipun demikian kita tidak bisa serta merta melarang generasi muda untuk menggunakan internet ataupun menonton tv, di abad 21 ini teknologi tidak dapat terpisahkan dari setiap lini 
kehidupan masyarakat. Sebenarnya sarana internet juga dapat memberikan dampak positif bagi moralitas generasi muda jika digunakan dengan bijak, misalnya dapat membantu mencari sumber belajar, melalui internet siswa dapat mengakses buku-buku elektronik, jurnal ataupun penelitian-penelitian terbaru yang dapat menambah wawasan serta pengetahuan. Untuk itu maka orang tua dan guru di daulat sebagai pihak yang paling bertangung jawab dalam mendidik moral generasi muda, bukan tanpa sebab anggapan tersebut muncul karena beberapa ahli seperti Lickona, 1991: 400; Marzuki, 2015: 66-70; dan Ki Hajar Dewantara, 2004: 70-74 menuliskan bahwa orang tua dan guru memiliki peran besar dalam pendidikan moral generasi muda. Untuk itu dalam artikel ini akan membahas bagai mana peran strategis dari orang tua dan guru untuk mendidik moral generasi muda.

\section{KAJIAN TEORI Hakikat Moral}

Moral berasal dari kata "mos" atau "mores" (jamak) dari Bahasa Latin yang berarti adat istiadat (Muchson, 2009: 17). Dalam Bahasa Yunani moral dikenal dikenal dengan kata "ethos" yang selanjutnya menurunkan istilah etika. Sependapat dengan pendapat tersebut Bertens (2013: 6) menuliskan kata moral secara etimologis sama dengan kata etika. Menurut Bertens arti kata moral dapat dilihat sebagai nomina atau adjektiva. Sebagai nomina, kata moral sama dengan arti etika yang pertama, yaitu nilai-nilai dan norma-norma yang menjadi pegangan bagi seseorang atau suatu kelompok dalam mengatur tingkah lakunya. Sebagai adjektiva, kata moral sama artinya dengan etis.

Bertens (2013: 6-7) menyimpulkan tiga arti kata etika. Pertama, etika berarti nilai nilai dan norma-norma moral yang menjadi pegangan bagi seseorang atau sesuatu kelompok dalam mengatur tingkah lakunya. Makna ini dirumuskan juga sebagai sistem nilai yang dapat berfungsi dalam hidup manusia perorangan maupun sosial. Kedua, etika berarti kumpulan asas atau nilai moral, yang disebut sebagai kode etik. Ketiga, etika berarti ilmu tentang yang baik atau buruk. Etika dalam arti yang ketiga ini sering disebut filsafat moral.

Berbeda pendapat dengan Bartein, Wibowo (2009: 160) menyatakan bahwa moral dan etika merupakan sesuatu yang berbeda. Menurutnya moral dan etika memiliki hubungan erat, tetapi keduanya memiliki sifat yang saling berbeda. Moral lebih merupakan suatu ajaran, wejanganwejangan, patokan-patokan, kumpulan peraturan, baik lisan maupun tertulis, tentang bagaimana manusia harus hidup dan bertindak agar menjadi manusia yang baik, sedangkan etika adalah cabang filsafat yang mengkaji secara kritis dan mendasar tentang ajaran-ajaran moral tersebut. Walaupun berbeda namun menurut Wibowo keduanya tidak bisa dipisahkan dari nilai dasar, pandangan hidup, atau filsafat hidup suatu masyarakat.

Magnis Suseno (1987: 19) mengatakan bahwa kata moral selalu mengacu pada baik buruknya manusia sebagai manusia, sehingga bidang moral adalah bidang kehidupan manusia dilihat dari segi kebaikannya sebagai manusia, hal itu sama dengan apa yang dikemukakan oleh Poerwodarminta dalam Hamid Darmadi (2009: 50) mengatakan moral merupakan ajaran tentang baik buruknya perbuatan atau kelakuan.

Pada artikel yang berjudul Profesional values and practive achieving the standards for QTS, yang ditullis James Arthur, Jon Davison dan Malcom Lewis (2005: 20) dituliskan "Morality is aboute rules, principles and ideals which have the potential to guide the choices of our actions and which provide a basic for justifying or evaluating we do". Dari 
kutipan tersebut dapat diartikan moralitas adalah tentang aturan prinsip yang dicitacitakan yang mampu menuntun untuk menentukan pilihan dalam bertindak atau membantu mengevaluasi tindakan yang telah kita lakukan.

Dari beberapa pendapat di atas dapat ditarik benang merah bahwa moral dapat juga dijadikan sebagai pedoman untuk memutuskan tindakan yang akan dilakukan seseorang, sependapat dengan hal itu Kaelan (2014: 85) mengungkapkan bahwa "moral adalah suatu ajaran-ajaran ataupun wejangan-wejangan, patokanpatokan, kumpulan peraturan, baik lisan maupun tertulis tentang bagaimana manusia harus hidup dan bertindak agar menjadi manusia yang baik".

Selain digunakan sebagai patokan moral juga digunakan sebagai tolak ukur untuk menentukan baik buruknya tindakan yang dilakukan seseorang. Sjarkawi (2006: 28) mengungkapkan bahwa moral diartikan sebagai sarana untuk mengukur benar tidaknya atau baik-tidaknya tindakan manusia. Reynolds \& Cerani(2007: 1612) Mengartikan bahwa tindakan moral merupakan suatu tindakan yang berasal dari perpaduan antara penalaran moral dan penilaian moral dari dalam diri seseorang.

Berdasarkan beberapa pendapat di atas dapat disimpulkan bahwa moral memegang peranan penting dalam kehidupan manusia, moral berhubungan dengan baik dan buruk terhadap tingkah laku manusia. Tingkah laku ini mendasarkan diri pada norma-norma yang berlaku dalam masyarakat. Seseorang dikatakan bermoral, bilamana orang tersebut bertingkah laku sesuai dengan norma-norma yang terdapat dalam masyarakat.

Agusto Blasi (1983:2) menuliskan "Morality is ultimately a characteristic of action, and moral development should lead to moral behavior". Dari kutipan di atas dapat dipahami jika moralitas merupakan suatu karakteristik puncak dari tindakan, dengan demikian berarti kualitas moralitas seseorang dapat dilihat dari tindakanya. Tanpa tindakan, moral hanya akan menjadi sebuah cita-cita baik. Moralitas tidak cukup hanya diketahui, moralitas membutuhkan tindakan nyata yang tercerimin dari perilaku seseorang sehari-hari. Perilaku tertentu di dalam kerangka konteks tertentu, dengan memperhatikan proses-proses batin akan melahirkan perilaku moral (Darmiyati Zuchdi, 2010: 51).

\section{Peran Orang Tua dalam Mendidik Moral}

Dalam mendidik seorang anak,keluarga merupakan tempat pertama (sekolah) bagi seorang anak untuk belajar tentang cinta, komitmen pengorbanan, dan keimanan. Di dalam keluarga juga mulai diajarkan dasar-dasar nilai moral sebelum anak mulai belajar pada keadaan lain yang ada di luar keluarganya. Hal itu sesuai dengan pendapatnya Lickona (2004: xxiv) bahwa ,The family is the first school of virtue. It is where we learn about love. It is where we learn about commitment, sacrifice, and faith in something larger than ourselves. The family lays down the moral foundation on which all other social institutions build.

Selain itu terdapat beberapa kajian lain yang dilakukan Narvaez \& Lapsey, 2009: 27; Ki Hajar Dewantara, 2004: 7074 serta Dimermen; 2009: 21 yang semuanya menyatakan bahwa keluarga memiliki pengaruh terhadap kepribadian anak. Pembentukan suatu prilaku dari seseorang dimulai dengan hubungan peduli dari rumah dan kemudian dilanjutkan sekolah. Seorang anak yang dirawat dengan perduli kemungkinan akan juga akan perduli untuk merawat orang lain dan terlibat sebagai warga negara dalam kehidupan moral masyarakat (Narvaez \& Lapsey, 2009: 159). Selain itu pembentukan pertimbangan moral dimulai sejak usia sanggat dini (Hanaford, 1985: 
85), sehingga keluarga memiliki peengaruh yang besar dalam moralitas anak.

Berdasar pendapat di atas maka
keluarga memiliki pengaruh bagi moralitas anak, keluarga sendiri memiliki model perilaku keluarga secara langsung maupun tidak langsung akan dipelajari dan ditiru oleh anak. Anak melihat dan menjadikan orang tua sebagai model untuk bersikap, bertutur kata, mengekspresikan harapan, tuntutan, dan kritikan satu sama lain, menanggapi dan memecahkan masalah, serta mengungkapan perasaan dan emosinya. Model perilaku yang baik akan membawa dampak baik bagi perkembangan anak demikian juga sebaiknya.

Selain ditiru oleh anak, cara orang tua dalam memberikan bimbingan, kasih sayang, apresiasi dan pengarahan pada anak yang berbeda-beda tiap keluarga, juga dapat mempengaruhi prilaku moral anak. Darcia Narvaez \& Daniel K. Lapsey (2009: 27) berpendapat bahwa Influence on the child's moral development as well, in particular, the tendency of the affection and appreciation of older people. Moral develop fundamental in shaping the moral life is the emoticon for the care received in early life is the care of the family, esspecially the biological parent.

Hal itu dapat dipahami bahwa, anak yang bermoral baik, biasanya dipengaruhi oleh kasih sayang dan apresiasi dari orang tua, untuk mengembangkan moral yang mendasar bagi kehidupan anak dimulai semenjak awal kehidupanya yaitu asuhan yang terutama berasal dari orang tua kandung. Senada dengan apa yang diungkapkan Narvaez dan Lapsey diatas, dari hasil meta analisis Hardy,Waker \& Gustavo (2008: 205) ditemukan fakta bahwa bahwa orang tua memegang peranan sentral dalam mempromosikan nilai-nilai kepada anak remaja, dengan begitu anak dapat menginternalisasikan nilai-nilai yang disosialisasikanya. Untuk itu orang tua dapat berperan dalam mendidik moral generasi muda salah satunya dengan cara menerapkan pola asuh yang baik. Hal itu dibuktikan oleh kajian yang dilakukan oleh Covey, (1997, p. 141); Lickona (2004, pp. 36-37); Launrence Steinberg dan Dornburch, (1996, p. 117); Walker \& Hennig, (1999, p. 359); Lemans, (2005, p. 270); Carlo dkk, (2007, p. 147); Lohaus, (2009, p. 449); dan Schroeder dkk, (2010, p. 64) yang semuanya menyimpulkan bahwa pola asuh memiliki peran yang penting untuk mempengaruhi penalaran moral dan perilaku pada anak dan remaja.

Pola asuh sendiri memiliki beberapa macam tipe yang masing-masing tipe memberikan dampak yang berbeda terkait dengan moralitas generasi muda. Penelitian yang dilakukan oleh Diana Baumrind pada tahun (1966, 1971, 1991), dapat menunjukan tiga pola asuh utama yang digunakan orang tua yaitu Pengasuhan Otoriter (authoritarian Parenting), Pengasuhan Otokratif (authoritative Parenting), dan Pola asuh permisif (Permisive Parenting). Dari berbagai pola asuh yang ada, Baumrind, 1966; Lickona, 2004: 67; dan Santrock, 2011: 78 sepakat menyebutkan bahwa pola asuh otoratif diangap memiliki efek paling bagus dalam perkembangan moral remaja. Pola asuh otoratif di anggap paling baik karena memberikan kebijakan batas terhadap tindakan yang dilakukan oleh anak.

Pengasuhan Otokratif (authoritative Parenting) pola asuh ini orang tua mendorong anaknya untuk menjadi mandiri, tetapi masih menempatkan batasan dan kontrol atas tindakan mereka. Pada berbagai hal orang tua sering untuk berdialog atau bermusyawarah dengan anaknya untuk memutuskan berbagai keputusan. Orang tua bersikap hangat dan memberikan dukungan kepada prilaku anak yang konstrukstif, anak dilatih untuk memiliki sikap mandiri dewasa, sesuai umur mereka. Dengan begitu potensi yang 
dimiliki anak akan dapat dimaksimalkan karena anak mendapatkan kebebasan untuk melakukan hal yang sesuai keinginanya (Diana Baumrind 1991).

Dengan demikian maka dapat dipahami bahwa dalam menjalankan peranya untuk mendidik moralitas generasi muda maka orang tua dapat berperan untuk mengasuh anak dengan pola otokratif, agar dapat memberikan dampak positif pada moralitas anak. Namun harus kita tahu bahwa untuk mendidik moralitas tidak cukup hanya mengandalkan orang tua melainkan juga membutuhkan peran dari pihak lain misalnya guru. Kajian dari Lickona, 1991: 400; Marzuki, 2015: 66-70; dan Ki Hajar Dewantara, 2004: 70-74 menunjukan bahwa kombinasi orang tua dan guru multak diperlukan untuk mendidik moral generasi muda.

\section{Peran Guru dalam Mendidik Moral}

Selain keluarga sebagai pihak pertama dalam mempengaruhi karakter, sekolah juga memiliki pengaruh dalam memperkuat nilai moral dan karakter positif yang diajarkan di rumah (Lickona, 1991: 400). Sependapat dengan Lickona, Wiliams berpendapat "is next to imposible to separate the teaching of value from schooling it self it is a part of scholing whether people are willing to acknowledge it or not." (2000: 34). Dengan demikian mendidik nilai tidak dapat dilakukan hanya oleh orang tua di rumah, melainkan harus ada peran dari sekolah. Hal yang sama diungkapkan $\mathrm{Ki}$ Hajar Dewantara (2014: 70), beliau mengelompokan tiga pusat pendidikan bagi anak yang salah satunya adalah pendidikan di sekolah.

Di sekolah guru merupakan faktor penting dalam kegiatan belajar mengajar, alokasi waktu terbesar siswa di sekolah digunakan untuk interaksi belajar mengajar dengan guru. Parker dkk (1998: 148) menyebutkan "Teacher will be among the chief stewards of this transformation", lebih lanjut ia menjelaskan bahwa guru merupakan “...key change agentsin school system...". Maka dari itu seharusnya guru dapat memaksimalkan peranya guna menanamkan karakter terutamanya tindakan moral siswa melalui interaksinya dengan siswa saat mengajar. Lickona (1991: 77-88) menjelaskan bahwa moralitas berhubungan dengan relasi cara orang saling memperlakukan. Dalam sebuah komunitas kecil seperti kelas, siswa memiliki dua macam hubungan, yakni: hubungan mereka dengan guru dan dengan sesama siswa, kedua macam hubungan ini bisa memberikan dampak yang positif maupun negatif dalam perkembangan karakter mereka. Lebih lanjut dijelaskan bahwa guru dapat menjadi seorang pembimbing etis dengan cara memberikan pengajaran moral dan pengarahan melalui penjelasan, diskusi penyampaian cerita, menunjukan semangat pribadi, dan memberikan umpan balik korektif ketika siswa mencoba menyakiti teman ataupun diri mereka sendiri.

Dengan demikian dapat dipahami bahwasanya guru merupakan pihak yang memiliki tugas berat dalam mendidik siswa, mendidik dalam hal ini diartikan sebagai suatu tindakan guna memunculkan suatu perubahan positif pada diri seseorang. Jika dilihat dari beberapa literatur seperti Kerr, 1999, p. 7; Doganay, 2012, p. 19; Patrick\&Vontz, 2001, p. 41; Cholisin, 2004, p. 14; Samsuri, 2011, p. 3; Mrnjaus, 2012, p. 82; Doganay, 2012, p. 33; Arthur, Davison \& Lewis, 2005, pp. 9-23; Fadil, Ismail, dan Etin, 2013, p. 3 semuanya menunjukan bahwa guru memiliki peran penting dalam mendidik moral siswanya.

Mengenai peran guru, Fadil, Ismail dan Etin (2013, p. 3) mengartikan peran merupakan perilaku yang diharapkan oleh orang lain, terhadap seseorang yang sesuai dengan kedudukannya dalam suatu sistem. 
Sedangkan De Jager, Mok, and Sipkema (2004) yang dikutip oleh Lunenberg, Dengerink, dan Korthagen menuliskan (2014, p. 6) "role as a cluster of more or less stringent expectations of the behaviour of a person in a certain position" jadi peran menurut Lunenberg, Dengerink, dan Korthagen adalah, harapan seseorang terhadap suatu posisi tertentu. Jika dihubungkan dengan guru, maka dapat disimpulkan peranan guru merupakan gambaran pola tingkah laku yang diharapkan dari berbagai interaksinya baik dengan siswa (yang utama), dengan guru lain maupun dengan staf lain (Sardiman, 2012, p. 143).

Menurut Marzuki\&Feriandi (2016) terdapat beberapa contoh peran yang dapat digunakan guru untuk mendidik moralitas generasi muda yakni

a. Motivator

Peranan guru sebagai motivator ini penting artinya dalam rangka meningkatkan kegairahan dan pengembangan kegiatan belajar siswa. Dalam peran ini guru harus dapat merangsang dan memberikan dorongan serta memberikan penguatan, kepada siswa untuk dapat melakukan tindakan moral yang baik. Pada peran guru sebagai motivator, Indikator yang dapat digunakan yakni: Memberikan motivasi kepada siswa dengan memberikan komentar dan masukan yang membangun, mendukung keinginan siswa dalam hal positif.

b. Director

Guru membimbing dan mengarahkan kegiatan belajar siswa sesuai dengan tujuan yang dicitacitakan. Dalam keadaan ini guru memberikan pengarahan kepada siswa untuk dapat melakukan kegiatan yang dapat melatih tindakan moral, misalnya guru mengarahkan siswa untuk berdoa sebelum mulai pelajaran. Berdoa juga merupakan sebuah tindakan moral. Ketika siswa tahu bahwa berdoa merupakan suatu aktivitas yang baik untuk dilakukan, namun belum tentu siswa mau melakukannya jadi guru harus megarahkanya sehingga dikemudian hari akan tercipta sebuah kebiasaan yang baik dan sulit untuk dihilangkan. Indikator yang ada pada peran ini guru: memberikan arahan untuk melakukan suatu tindakan yang baik, Guru memberikan saran siswa untuk melakukan kebaikan.

c. Inisiator

Dalam menjalankan peran ini, guru harus memunculkan ide-ide kreatif, serta memunculkan nilai-nilai positif yang dapat ditiru oleh siswa dalam pendidikan dan pengajaran di luar maupun di dalam kelas. Pada peran ini guru juga memerankan diri sebagai seseorang yang dapat dicontoh, untuk menumbuhkan moralitas yang baik bagi siswa guru harus memberikan contoh dengan bersikap sesuai dengan moralitas yang berlaku. Indikator untuk peran ini adalah : Menampilkan sikap yang positif sesuai norma hukum, Menampilkan sikap yang positif sesuai norma sosial.

d. Informator

Dalam peran ini guru menjadi salah satu sumber informasi bagi siswa, guru dapat memberikan informasi mengenai perilaku-perilaku yang terpuji dan prilaku yang tidak terpuji. Hal penting agar dapat membantu siswa untuk mengembangkan penalaran moralnya terhadap suatu tindakan. Dengan demikian siswa diharapkan dapat mepertimbangkan dampak dari suatu tindakan yang akan dilakukan, baik berupa dampak positif maupun negatif. Indikator dari peran ini adalah : Guru menyampaikan informasi kepada siswa mengenai dampak perbuatan tidak terpuji, guru menyampaikan informasi kepada 
siswa mengenai contoh akibat perbuatan terpuji.

e. Evaluator

$$
\text { Peran guru sebagai }
$$
evaluator mengharuskan guru untuk selalu memantau perkembangan siswanya, dengan evaluasi didapatkan feed back dari proses belajar mengajar (Muhammad Uzer Usaman, 2006: 12). Evaluasi tidak hanya mencakup nilai kognitif semata, melainkan juga sikap, agar dapat memenuhi tujuan utama pendidikan yaitu pintar dan baik. Dengan demikian hendaknya penilaian diarahkan kepada perubahan kepribadian anak didik agar menjadi manusia susila yang cakap (Syaiful Bahri Djamarah \& Aswan Zain, 2010: 48). Pada peran ini guru memulai dengan menyususun instrumen penilaian, kemudian melaksanakan penilaian dalam berbagai bentuk dan jenis penilaian untuk mengetahui dan mengukur prestasi siswa. Indikator pada peran ini adalah : Memberikan laporan penilaian siswa, Memberikan saran kepada siswa yang memiliki prilaku kurang baik.

\section{f. Fasilitator}

Dalam peranya sebagai fasilitator, guru harus menyediakan dan memberikan fasilitas untuk mempermudahkan proses belajar mengajar. Fasilitas dalam hal ini tidak hanya berupa fisik seperti ruang kelas yang memadai, media belajar namun juga termasuk fasilitas psikis yang dapat mendukung kenyamanan batin siswa dalam belajar. Dengan merasa nyaman siswa akan fokus untuk memperhatikan pelajaran, tidak memperhatikan hal lain yang mungkin tidak bermanfaat atau bahkan merugikan. Indikator dalam peran ini adalah: guru menggunakan media yang beragam saat mengajar, guru mampu membuat siswa merasa nyaman ketika belajar di kelas.

\section{SIMPULAN}

Dari berbagai ulasan diatas maka dapat disimpulkan bahwa peran yang dapat dilakukan guru guna mendidik moral generasi muda seperti memotivasi, mengarahkan, menjadi inisiator, menjadi informator, menjadi evaluator, serta menjadi fasilitator yang baik bagi siswa maka tindakan moral siswa juga akan semakin baik. Selain itu diperlukan juga peran oang tua untuk dapat mengasuh anaknya dengan pola asuhan yang tepat yakni otokraitf. yang perlu diperhatikan adalah dalam mendidik moralitas generasi muda tidak dapat dibebankan pada salah satu pihak semata (orang tua/guru) melainkan harus dilakukan secara berkesinambungan dan bersama-sama. Selain itu terdapat faktor lain pula yang dapat mempengaruhi moralitas genarasi muda, misalnya lingkungan, namun faktor lingkungan akan dapat di minimalis dampak negatifnya jika orang tua dan guru mampu memaksimalkan peranya baik di sekolah maupun di rumah.

\section{DAFTAR PUSTAKA}

Bartens, K. (1993). Etika. Jakarta : PT Gramedia Pustaka Utama.

Baumrind, D. (1966). Effects of authoritative parental control on child behavior. Child Development Vol 4, hal 887907.

Baumrind, D. (1991). Effective parenting during the early adolescent transition. In P.E. Cowan and E.M Hetherington (Eds.). Advances in family research, Vol. 2 Hal 111- 163.

Baumrind, D. (1991). The influence of parenting style on adolescent competence and substance use. Journal of Early Adolescence, Vol. 11, Hal 56-95. 
Baumrind, D. (1971). Current patterns of parental authority. Developmental Psychology Monographs, 4, 2, Pt. 2.

Blasi, A. (1983). Moral cognition and moral action: A theoretical perspective. Developmental Review Vol 3, hal 178-210.

Carlo Gustavo,dkk (2007): Parenting Styles or Practices? Parenting, Sympathy, and Prosocial Behaviors Among Adolescents, The Journal of Genetic Psychology: Research and Theory on Human Development, 168:2, halaman 147-176

Cholisin. (2004). "Konsolidasi Demokrasi Melalui Pengembangan Karakter Kewarganegaraan," Jurnal Civics, Vol. 1, No. 1, Juni,halaman. 14-28

Cholisin. (2011). Peran Guru pkn dalam pendidikan karakter. Makalah disampaikan pada kuliah umum jurusan PPKn FKIP UAD Yogyakarta, 5 Februari 2011

Covey, S. (1997). The 7 habits of highly effective families. New York, NY: Golden Book.

Darcia Narvaez \& Daniel K. Lapsey. (2009). Moral Identity, moral fungtioning, and the development of moral character, Burlington: Academic Presss

Darmiyati Zuchdi. (2010). Humanisasi pendidikan: menentukan kembali pendidikan yang manusiawi. Jakarta: Bumi Aksara

Dimerman, Sara. (2009). Character is a key: how to unlock the the best in our children and our selves. Mississauga: John Wiley \& Sons Canada, Ltd

Doganay, Ahmed. (2012). A curriculum framework for active democratic citizenship education.

Dalam Print, Murray \& Large, Dirk (2012). Schools Curriculum and civic Education for Building Democratic citizens. Rotterdam

Fadil Yudia Fauzi, Ismail Arianto, Etin Solihatin. (2013). Peran Guru Pendidikan Pancasila Dan Kewarganegaraan Dalam Upaya Pembentukan Karakter Peserta Didik. Jurnal Ppkn UNJ Online. Volume 1, Nomor 2, Tahun 2013

Hamid Darmadi (2009). Dasar Konsep Pendidikan Moral Yogyakarta : Alfa beta

Hardy,Waker \& Gustavo (2008). Parenting dimensions and adolescents internalisation of moral values. Journal of Moral Education. Volume 37 nomor 2, halaman 205-223

James Arthur, Jon Davison \& Malcolm Lewis. (2005). Profesional values and practice achieving the standards for QTS. London and New York. Rouledge Falmer

James Arthur, Jon Davison \& Malcolm Lewis. (2005). Profesional values and practice achieving the standards for QTS. London and New

Kaelan. (2014). Pendidikan pancasila.Yogyakarta

Paradigma

Kerr, D. (1999). "Citizenship education in the curriculum: An international review," The School Field. Vol. 10, Hal 3-4

Ki Hajar, Dewantara. Bagian pertama : Pendidikan (2004) cetakan ke 3. Yogyakarta. Majelis Luhur Persatuan Taman Siswa

Lawrence J. Walker \& Karl H. Hennig (1999) Parenting Style and the Development of Moral Reasoning, Journal of Moral Education, 28:3, 359-374

Lickona, T.(2004). Character matters: how to help our children develop good judgment, integrity, and 
other essential virtues. Newyork: Bantam Books

Lickona, T. (1991). Educating for character. New York: Bantam Books.

Lohaus, Arnold. Marc Vierhaus dan Juliane Ball. (2009). Parenting Styles and Health-Related Behavior in Childhood and Early Adolescence, Journal of Early Adolescence Volume 29 Number 4 halaman 449-475

Lunenberg, Dengerink, dan Korthagen (2014). The Professional Teacher Educator Roles, Behaviour, and Professional Development of Teacher Educators. Terdam: Sense Publiser

Lurence Steinberg, B. Brown dan S.M. Dornbusch (1996) Beyond the classroom: why school reform failed and what parents need to do. Newyork: Simon\&Schuster

Marzuki. (2015). Pendidikan karakter islam. Yogyakarta: Amzah

Mrnjaus, Kornelij. (2012). Teacher Competences For Education For Democratic Citizenship. Dalam John J. Patrick dan Robert S. Leming (eds). Principles and practices of democracy in the education of social teacher, Blomington, in: ERIC Clearinghouse for social Studies/Social Science Education, ERIC Clearinghouse for International Civic Education, and Civitas, Hal 39. 64

Muchson, A.R. (2009). Dimensi Moral dalam Pendidikan

Kewarganegaraan. Jurnal Civics Media Kajian

Kewarganegaraan. Volume 6, Nomor 1,16-28

Muhamad, Uzer Usman. (2006). Menjadi guru profesional. Bandung: Remaja Rosdakarya
Parker. Walker dkk. (2008). Making It Work: Implementing Multidimensional Citizenship dalam John J. Cogan dan Ray Derricott, Citizenship for the 21st Century: An Introduction Perspectives on Education, London: Kogan Page Ltd, pp.135-154.

Patrick J. Leman, (2005). Authority and moral reasons: Parenting style and children's perceptions of adult rule justifications. International Journal of Behavioral Development. 2005, 29 (4), 265-270

Patrick.J, John dan Vontz, S, Thomas (2001). "Componen of education for democratic citizenship in the preparation of social teacher". Dalam John J. Patrick dan Robert S. Leming (eds). Principles and practices of democracy in the education of social teacher, Blomington, in: ERIC Clearinghouse for social Studies/Social Science Education, ERIC Clearinghouse for International Civic Education, and Civitas. Hal 3964

Reynolds. Scott J. and Ceranic. Tara L.(2007) The Effects of Moral Judgment and Moral Identity on Moral Behavior: An Empirical Examination of the Moral Individual. Journal of Applied Psychology. Vol. 92, No. 6, 1610-1624

Robert V. Hannaford. (1985). Moral reasoning and action in young children. The Journal of Value lnquiry 19:85-98

Samsuri (2011). Mengapa (Perlu) pendidikan karakter? kaji ulang pengalaman di fise universitas negeri yogyakarta. Bahan sosialisasi mata kuliah pendidikan karakter di FISE 
UNY di Wonosobo, 14 Januari 2011

Santrock, Jhon. (2011). Educational Psychology. New York: The Mc Graw Hill Companies

Santrock. John ( 2010). Life Span Development Thirteenth Edition. New York: The McGraw-Hill

Sardiman. (2012). Interaksi dan Motifasi Belajar Mengajar. Jakarta: Rajawali Pers.

Schroeder, Ryan. (2010) Parenting and Adult Criminality: An Examination of Direct and Indirect Effects by Race Journal of Adolescent Research . Volume25 halaman 64-98

Suseno Magnis, Frans. (1987). Etika Dasar: Masalah-masalah Pokok Filsafat Moral, Yogyakarta: Kanisius.

Syaiful Bahri Djamarah \&Aswan Zain. (2010). Strategi belajar mengajar.Jakarta: Rineka Cipta

Syarkawi. (2006). Pembentukan kepribadian anak, Jakarta: Bumi aksara 